DOI: https://doi.org/10.24164/prosiding.v3i1.10

\title{
RELIGI KAHARINGAN SEBAGAI JEJAK AUSTRONESIA PADA ORANG DAYAK
}

\author{
The Kaharingan Religion \\ as Trace of Austronesian of Dayak's People
}

\author{
Hartatik \\ Balai Arkeologi Kalimantan Selatan \\ Jalan Gotong Royong RT 03/06 Mentaos, Banjarbaru, Kalsel \\ E-mail: tatitatibalar@gmail.com
}

\begin{abstract}
The Dayaks are the oldest inhabitants of the island of Borneo until now. There are hundreds of Dayak families separated by geographical environment and language differences, but basically they have the almost similarity culture. The purpose of this study is to explain the Kaharingan religion that are still ongoing of dayak's people in Kalimantan. The method used is descriptive analytic with ethnoarchaeological approach. Primary data were obtained from the Balai Arkeologi Kalimantan's research between 2006 until 2019, supported by a literature review. Austronesian traditions that still continue as belief in ancestral spirits manifested in the form of spirit boats. The tradition survives because the religion concept which has strong roots related to the history of the ancestors and transformed be spirit. However, along with the times, the tradition is endangered.
\end{abstract}

Keywords: Austronesian, Dayak, custom, religious, and spirit boat.

\begin{abstract}
AbSTrak
Orang Dayak merupakan penduduk tertua penghuni Pulau Kalimantan yang kini masih ada. Ada ratusan rumpun Dayak yang dipisahkan oleh lingkungan geografis dan perbedaan bahasa, tetapi pada dasarnya mereka mempunyai budaya yang hampir sama. Tulisan ini bertujuan menjelaskan kepercayaan Kaharingan sebagai salah satu kepercayaan leluhur yang masih berlangsung pada kehidupan orang Dayak di Kalimantan. Metode yang digunakan adalah deskriptif analitik dengan pendekatan etnoarkeologi. Data tulisan ini diperoleh dari penelitian Balai Arkeologi Kalimantan Selatan antara tahun 2006 hingga 2019 yang didukung dengan kajian literatur. Kepercayaan terhadap roh leluhur sebagai jejak Austornesia diwujudkan dalam bentuk perahu arwah. Tradisi tersebut bertahan karena konsep religi yang sudah kuat mengakar berkaitan dengan sejarah leluhur dan telah menjelma menjadi semangat. Namun demikian, seiring dengan perkembangan zaman, tradisi tersebut kini terancam punah.
\end{abstract}

Kata kunci : Austronesia, Dayak, adat, religi, dan perahu arwah.

\section{PENDAHULUAN}

$\mathrm{P}$ enutur bahasa Austronesia kini tersebar dari Madagaskar di ujung barat Samudra Hindia hingga Pulau Paskah di ujung Timur Samudra Pasifik, dan dari Taiwan
Mikronesia hingga Selandia Baru. Budaya yang ditinggalkan oleh bangsa berpenutur Austronesia ini kemudian dikenal sebagai budaya Austronesia. Budaya Austronesia 
diawali oleh budaya neolitik dengan berbagai variasinya, bahkan sebagian terus berlanjut hingga kini (Bellwood, 2016; Tanudirjo, 2016).

Berdasar ciri-ciri etnografis, orang Dayak merupakan sisa-sisa dari imigran Proto Melayu (sebelum kedatangan Orang Melayu) yang dikaitkan dengan migrasi bangsa Austronesia. Kedatangan kelompok bangsa Austronesia ke Nusantara terutama ke Pulau Borneo (Kalimantan termasuk Sabah, Brunei) dan Sulawesi diperkirakan terjadi 2500 - 2000 SM (Bellwood 2000). Sebelum kedatangan orang berpenutur bahasa Austronesia, Kalimantan dihuni oleh ras Austromelanesid yang merupakan percampuran antara Austrauloid dan Melanesid. Hal itu sesuai dengan temuan manusia tertua berupa ras Austromelanesid di Gua Babi, Kalimantan Selatan sekitar 5000 BP (Widianto \& Handini 2003).

Orang Dayak sebagai penduduk tertua di Kalimantan hingga kini masih memegang teguh tradisi leluhur. Dari sekian data etnografi yang masih bertahan, kepercayaan terhadap roh leluhur merupakan tradisi yang unik di tengah modernitas. Adapun tujuan tulisan ini adalah untuk mengetahui perkembangan religi Kaharingan sebagai jejak budaya Austronesia yang masih berlangsung di wilayah Kalimantan.

\section{PEMBAHASAN}

Periodisasi Austronesia di Indonesia dibagi dalam tiga kelompok besar berdasar peristiwa besar yang menyebabkan perubahan di berbagai bidang. Periode pertama adalah Austronesia Prasejarah yaitu sejak kehadiran penutur Austronesia hingga sekitar 2000 BP yang ditandai dengan budaya neolitik. Periode kedua adalah Austronesia Protosejarah (2000 BP - 400
Masehi), sedangkan yang ketiga adalah Austronesia masa kini yaitu sejak masa kemerdekaan hingga sekarang (Simanjuntak 2011). Adapun data etnografi tradisi orang Dayak dalam artikel ini merupakan bagian dari Austronesia masa kini.

Keberadaan perahu sebagai transportasi air dan simbol perjalanan roh telah ada sejak ratusan bahkan mungkin ribuan tahun yang lalu. Di Kalimantan, motif perahu ditemukan pada lukisan gua di Pegunungan Meratus bagian tenggara yaitu di Gua Jauhari 1 di Kalumpang Hulu, Kotabaru. Dari analogi temuan arang dari ekskavasi di Gua Jauhari 1 yang diduga semasa dengan lukisan perahu diperoleh angka $1500 \mathrm{BP}$ atau berada pada sekitar tahun 500 Masehi (Fajari, et.al., 2019). Selain Kotabaru, di Kawasan Pegunungan Meratus sisi tenggara, lukisan perahu juga terdapat di Liang Kacamata, Kecamatan Mentewe Kabupaten Tanah Bumbu. Di Pantai timur Kalimantan, lukisan perahu ditemukan di Gua Jeriji Saleh di Tanjung Mangkalihat, Kutai Timur yang dibuat sekitar 40.000 BP (Aubert et al. 2018), kedatangan orang Austronesia ke wilayah Indonesia.

Keberadaan perahu pada lukisan purba menunjukkan bahwa perjalanan migrasi bangsa Austronesia dan para pendahulunya menempuh lautan luas memerlukan keahlian dan pengetahuan tentang teknologi pelayaran. Data etnografi adanya jenis-jenis perahu dari yang paling sederhana seperti rakit bambu, sampan (perahu kecil), hingga perahu bercadik menunjukkan bahwa orang Austronesia telah mengenal perahu sebagai transportasi air pada masa itu (Tanudirjo, 2005).

Perkembangan kehidupan manusia mengalami beberapa tahapan, mulai dari mengembara, tinggal di gua dan ceruk, tepi 
pantai hingga menetap. Setelah mengenal bercocok tanam, orang Austronesia mulai hidup menetap. Kehidupan menetap dalam satu kelompok atau perkampungan sehingga mereka mempunyai banyak waktu luang untuk kontemplasi hingga mendorong berkembangnya konsep kepercayaan. Tahap ini ditandai dengan adanya sistem penguburan, bekal kubur, dan mitos-mitos yang diwariskan turun temurun. Kehidupan menetap telah membuat banyak perubahan pada kehidupan orang Austronesia (Simanjuntak 2011).

\section{Religi Orang Dayak}

Dalam kebudayaan universal, religi merupakan salah satu unsur dari enam unsur kebudayaan lainnya. Unsur religi terbagi atas empat komponen, yaitu umat, konsep religi, ritus, peralatan upacara, dan emosi keagamaan (Koentjaraningrat 2000). Kepercayaan akan roh leluhur terwujud dalam bentuk upacara yang berkaitan dengan daur hidup (kelahiran, perkawinan, kematian), upacara panen, tolak bala dan pengobatan. Keberlanjutan tradisi Austronesia yang paling kental adalah dalam hal konsep kepercayaan terhadap kekuatan di luar diri manusia, terutama roh leluhur.

Sebagian besar orang Dayak kini telah menganut agama Kristen, tetapi di beberapa daerah pedalaman masih banyak yang menganut kepercayaan leluhur. Nama kepercayaan pada tiap daerah berbeda, misalnya Hedon, Telon, bahkan sebagian besar tidak bernama tetapi hanya disebut sebagai agama leluhur atau agama asli. Orang Dayak Ngaju, Maanyan, Lawangan, di Kalimantan Tengah menyebut kepercayaan turun temurun yang disebut Kaharingan. Menurut asal katanya, Kaharingan berasal dari kata dasar haring dengan prefiks ka- dan sufiks -an sehingga membentuk kata sifat yang berarti ada dengan sendirinya atau sesuatu yang tidak diketahui asal muasalnya tetapi selalu ada di mana-mana. Istilah Kaharingan ini baru muncul pada abad ke-20 yang digagas oleh tokoh adat dan intelektual Dayak Ngaju sebagai sebuah identitas religius masyarakat Dayak, terutama di Kalimantan Tengah (Rampai 1983).

Tradisi yang unik dari masyarakat Dayak Ngaju penganut Kaharingan adalah perlakuan terhadap orang yang meninggal dunia. Dalam konsep Kaharingan, sebuah kematian dianggap sebagai masa transisi di mana roh si mati harus dipersiapkan dan diantarkan menuju ke alam roh. Kematian merupakan proses dilahirkan kembali untuk menuju kehidupan baru menyatu dengan roh leluhur di lewu tatau yang damai, kaya, dan sentosa. Untuk sampai ke tujuan tersebut, arwah harus melalui beberapa perjalanan yang panjang dan penuh rintangan, sehingga keluarga yang ditinggalkan perlu melakukan ritual untuk mengantarkan roh agar sampai ke tempat yang dituju. Perjalanan arwah dimulai ketika orang meninggal dunia, kemudian dikuburkan dalam tanah dengan wadah kubur berupa raung atau peti mati berbentuk perahu. Orientasi kubur primer orang Dayak adalah barat timur dengan kepada di sisi timur menghadap barat (arah matahari tenggelam) sebagai. Kematian dianggap sebagai awal kehidupan baru seperti matahari tenggelam di sisi barat yang akan muncul lagi di sis timur. Kehidupan dalam kubur inilah yang disebut lewu pasahan raung. Dari alam kubur arwah melanjutkan perjalanan ke lewu nalian lanting yang berarti tempat penantian. Dari tempat ini arwah masih menunggu untuk diantar menuju alam roh (disebut lewu tatau) melalui upacara penguburan kedua yang disebut tiwah (Hartatik, 2002b). 
Tiwah dilaksanakan bagi yang mampu, tetapi bagi yang tidak mampu dapat melakukan upacara tiwah kecil atau nyorat. Dalam tiwah kecil, inti ritual adalah mengantarkan arwah ke negeri asalnya yang disimbolkan dengan kehadiran banama tingang yaitu perahu dengan bagian ujungnya berbentuk kepala burung enggang dan ekor Naga. Dengan perahu banama tingang, pemimpin upacara yang disebut balian atau pesor menceritakan kembali kehidupan si mati dan perjalanan roh menuju negeri asalnya (Schärer, 1963, Hartatik, 2001).

Dalam konsep kepercayaan Dayak Meratus, Maanyan dan Lawangan, upacara kematian pada hakekatnya adalah mengantarkan arwah ke negeri asalnya yang terletak di puncak gunung. Nama gunung ini berbeda-beda untuk setiap sub suku, yaitu Gunung Halo-Halo untuk Dayak Meratus, Gunung Lumut untuk Dayak Maanyan, dan Lawangan. Arwah menuju ke tempat asalnya dengan naik perahu, karena untuk menuju ke gunung harus melewati sungai besar atau laut. Diyakini bahwa setelah upacara selesai, maka arwah tersebut telah bersatu dengan para leluhur dan telah menjadi pelindung bagi keluarga yang masih hidup (Hartatik 2017).

Dalam tradisi Dayak Meratus, ritual yang dilaksanakan secara besar dan meriah adalah upacara panen yang disebut baharin dan bawanang, sedangkan dalam tradisi Dayak Ngaju adalah upacara penguburan kedua yang disebut tiwah. Simbol-simbol kepercayaan hadir dalam upacara besar mereka, baik upacara kehidupan maupun kematian. Burung enggang sebagai simbol penguasa dunia atas dan naga atau tambon (sejenis ular air) sebagai simbol penguasa dunia bawah dihadirkan di atas sandong, tiang pantar dan sanggaran. Kematian dianggap sebagai awal perjalanan menuju ke alam arwah dengan kendaraan banama tingang (perahu arwah) yang disertakan dalam ritual kematian adat Dayak Ngaju. Dalam adat Dayak Meratus, bentuk naga, burung enggang dan perahu hadir dalam tiap upacara (aruh) panen bawanang dan baharin dengan digantung di tempat upacara (langgatan). Wadah sesaji berbentuk perahu dihanyutkan di sungai pada hari terakhir aruh, sebagai simbol kendaraan yang mengantar arwah kembali ke tempat asal setelah menghadiri pesta adat (Hartatik 2017).

Kedatangan nenek moyang dengan menggunakan perahu terekam dalam syair mantra balian beberapa suku Dayak, antara lain Bahau - Modang yang memohon kepada Dewa Batara, dan legenda suku Dayak Kapuas Buhang yang kemudian menyebar hingga wilayah Landak, Sanggau, dan Serawak (Bondan 1953). Simbol perahu hadir dalam ritual panen baharin (panen padi dari lahan baru), bawanang (panen padi dari lahan lama), upacara pengobatan orang Dayak Meratus, maupun upacara kematian orang Dayak Ngaju. Dalam ritual upacara bawanang dan baharin Suku Dayak Meratus, simbol perahu sebagai kendaraan arwah hadir dalam bentuk wadah sesaji bentuk miniatur perahu kayu dan perahu dari daun enau yang bagian ujungnya berbentuk naga dan burung enggang sehingga disebut perahu banaga. Miniatur perahu kayu berisi sesaji tersebut digantung di tempat upacara, kemudian pada akhir upacara dihanyutkan ke sungai sebagai tanda mengantar arwah pulang kembali ke tempat asalnya (setelah menghadiri upacara). Hadirnya simbolsimbol perahu, naga, dan burung enggang menjadi tanda bahwa ketiga benda tersebut merupakan ikon penting bagi orang Dayak Meratus, representasi dari keyakinan dan sejarah sang leluhur (Hartatik 2017). 
Kendaraan arwah dalam bentuk wadah kubur sekunder menyerupai perahu, di tiap daerah mempunyai variasi bentuk dan nama. Dayak Ngaju menyebutnya sandong (Gambar 1), sedangkan Dayak Maanyan, Lawangan, dan Benuaq menyebutnya keriring (Gambar 2), ada juga tambak. Data arkeologis berupa sandong tua berada di situs Nahan Biru dan Natay Kunang, keduanya merupakan keleka (bekas kampung). Dari data etnografi dan silsilah keluarga diketahui bahwa sandong Nahan Biru dan di Natay Kunang sudah ada sejak masa kolonial Belanda (Kusmartono 2005). Sandong masih berlanjut penggunaannya pada masyarakat Ngaju penganut Kaharingan Kalimantan Tengah sisi selatan.

Dalam ritual kematian Dayak Ngaju, peti mati untuk kubur primer dan sandong sebagai kubur sekunder dihiasi dengan gambar burung enggang dan naga. Burung enggang merupakan simbol dunia atas yang dipersonifikasikan sebagai laki-laki, sedangkan naga merupakan simbol dunia bawah yang dipersonifikasikan sebagai perempuan. Perahu sebagai simbol kendaraan, sedangkan naga dan burung enggang sebagai kesatuan dan keseimbangan kosmos (Schärer 1963).

Keseimbangan kosmos merupakan inti dari konsep religi Kaharingan untuk menjaga keseimbangan alam sekitar. Dalam konsep keseimbangan itulah, maka religi orang Dayak berbentuk aturan adat, pamali, dan denda adat bagi pelanggarnya. Meskipun upacara adat kematian sudah ditinggalkan tetapi aturan adat masih dilaksanakan, misalnya adat berpantang setelah upacara kematian.

Adat berpantang setelah kematian adalah dilarang memakai pakaian baru, bicara keras, melakukan jual beli, dan menyalakan api. Demikian juga setelah upacara panen, tolak bala, dan pengobatan terdapat pantang tidak boleh menerima tamu, berladang, dan berburu. Siapa saja yang melanggar pantangan tersebut maka akan dikenakan denda adat.

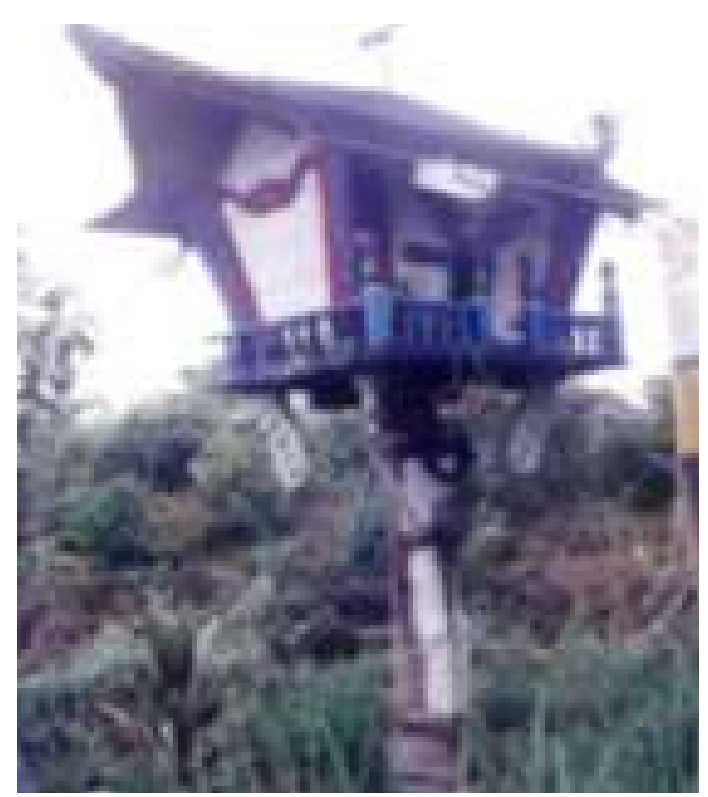

Gambar 1. Sandong, kubur sekunder Dayak Ngaju di Kotawaringin Timur, Kalteng (Sumber: Dokumen Balar Kalsel)

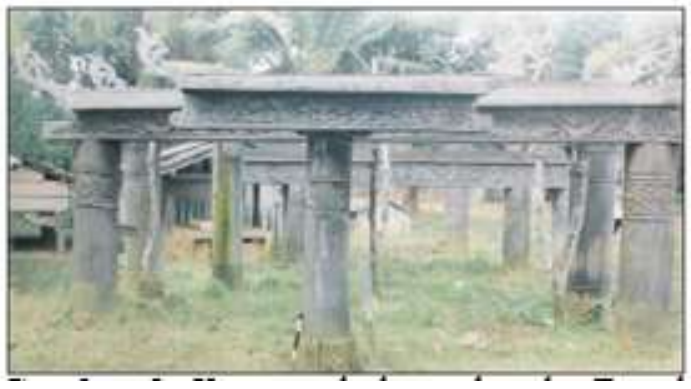

Gambar 2. Keriring, kubur sekunder Dayak Benuaq di Kutai Barat, Kaltim (Sumber: Dokumen Balar Kalsel).

Meskipun sebagian besar orang Dayak kini telah memeluk agama, tetapi sebagian besar masih percaya pada kekuatan roh leluhur yang dapat berpengaruh pada kehidupan manusia. Orang Dayak yang tinggal di kota pun masih percaya adanya pidara (roh yang masih mengembara) dapat mengganggu manusia sehingga disebut 
kepidaraan yang hanya bisa diobati dengan ritual adat. Orang Dayak Ngaju percaya adanya patahu dalam bentuk batu, atau tajahan dalam bentuk patung kayu sebagai penjaga kampung. Orang Dayak Taman dan Kanayatn di Kalimantan Barat percaya pada pantak (patung kayu) perwujudan roh leluhur (Hartatik 2006), seperti halnya patung pamindara pada orang Dayak Selako (Yondri 2003). Demikian juga keberadaan keramat sebagai tempat memohon hajat dan perlindungan yang ada hampir di semua desa pada permukiman orang Dayak.

Keberadaan perahu sebagai simbol kendaraan arwah dalam ritual adat kematian, upacara panen, dan pengobatan pada orang Dayak merupakan bukti bahwa religi tidak lepas dari simbol. Religi orang Dayak berupa kepercayaan terhadap roh leluhur merupakan bagian dari kebudayaan yang dibentuk dan diakui bersama oleh masyarakat Dayak. Budaya bukan merupakan milik individu tetapi milik bersama yang terus berkembang dan dimaknai (Keesing 1990). Kebudayaan tidak lepas dari simbol, karena pada dasarnya kebudayaan adalah kumpulan dari simbol dan makna yang dimiliki bersama oleh suatu kelompok. Kepercayaan terhadap roh leluhur diwujudkan dalam bentuk simbol-simbol dalam ritual. Geertz menyebut bahwa mempelajari upacara dalam konteks kebudayaan sebenarnya mempelajari simbol-simbol (Geertz 1973, 2012). Dalam konsep religi, peralatan upacara dihadirkan dalam bentuk simbolsimbol yang merupakan perwujudan dari konsep yang diyakini serta makna yang melatarbelakanginya. Religi orang Dayak diwariskan secara turun temurun sehingga konsep kepercayaan mereka tidak lepas dari perjalanan nenek moyang. Dari mana mereka berasal, dan ke mana mereka akan kembali setelah kehidupan di dunia ini menjadi bagian penting dalam ritual orang Dayak.

Dari tujuh unsur kebudayaan universal yang terdiri atas bahasa, sistem pengetahuan, organisasi sosial, peralatan hidup dan teknologi, sistem mata pencaharian, sistem religi, dan kesenian (Koentjaraningrat 2000), religi merupakan unsur kebudayaan yang paling sulit berubah dibandingkan dengan unsur budaya yang lain. Dalam pendekatan interpretatif Geertz, religi dalam sistem kebudayaan merupakan sistem simbol yang bertindak untuk memantabkan suasana hati dan menjadi motivasi yang kuat, mendalam dan sehingga mampu bertahan lama. Hal tersebut karena telah terjadi formulasi antara tatanan dasar alam dan kehidupan yang menyelimuti konsepsi tersebut dengan kondisi faktual sehingga suasana hati dan motivasi yang ditimbulkannya terasa nyata (Geertz, 2012 ; Alam, 2014).

Sebaliknya, perubahan tradisi dipengaruhi oleh beberapa faktor, baik faktor internal maupun eksternal. Faktor internal berasal dari dalam diri masyarakat yang bersangkutan,yaitu sikap menerima atau menolak terhadap sesuatu yang baru. Adapun faktor eksternal berasal dari luar masyarakat yang bersangkutan, misalnya demografi, perubahan iklim, perubahan lingkungan, perdagangan, dan kebijakan penguasa (Gerritsen 2008). Dalam teori kebudayaan, sesuatu yang baru akan membawa dampak bagi masyarakat yang bersangkutan. Dalam konsep akulturasi, proses sosial timbul antara kelompok manusia dengan suatu kebudayaan tertentu (Koentjaraningrat 2000).

Pengaruh kehadiran agama baru, terutama Kristen dan Islam telah merubah pola pikir mereka tentang upacara kematian Kaharingan. Penguburan yang semula diletakkan di atas ceruk gua diangap tidak 
manusiawi sehingga diganti dengan kubur dalam tanah. Demikian juga dalam upacara kematian wara (penguburan sekunder) yang semula menggali tulang yang telah dikuburkan, kini disederhanakan dengan tanpa menggali kubur. Sebagai gantinya, kehadiran tulang dan tengkorak si mati disimbolkan dengan buah kelapa. Pada sisi lain, orang Dayak masih melakukan kegiatan ladang berpindah dengan ritual-ritualnya mulai dari masa membuka lahan hingga panen. Demikian juga upacara pengobatan masih dilakukan secara adat, meskipun sudah ada Puskesmas atau bidan desa. Pengobatan dengan menghadirkan sosok balian sebagai perantara dengan arwah leluhur masih menjadi pilihan.

Meleburnya kepercayaan Kaharingan sebagai agama Hindu Kaharingan sejak tahun 1980, sebenarnya hanya dalam tataran formal. Agama Hindu Kaharingan "memaksa" Kaharingan menjadi agama baru dengan satu Tuhan Ranying Hatalla Langit, kitab suci Panaturan, dan bangunan balai basarah sebagai tempat ibadah dengan hari besar yang diadaptasi dari agama Hindu di Bali (Baier 2007). Bagaimanapun juga, Kaharingan adalah kepercayaan leluhur yang lahir dari perjalanan kearifan nenek moyang dengan alam sekitar. Dalam ajaran kepercayaan Kaharingan, Tuhan yang monoteisme tidak dapat disebut, kitab suci hanya ada dalam hati, tempat ibadah ada di semua jengkal tanah, dan hari besar ada dalam bentuk syukur panen dan mengantar arwah ke alam keabadian. Oleh karena itu, Hindu Kaharingan sebagai agama baru hanya dikenal dan dijalani oleh orang Dayak berusia muda karena adanya pendidikan formal agama Hindu Kaharingan di sekolah. Tetapi jauh di pedalaman, orang Dayak tetap sebagai orang Kaharingan yang berpegang pada ajaran leluhur, bukan agama baru yang diformalkan.

\section{SIMPULAN}

Data etnografi menunjukkan bahwa penguburan orang Dayak berorientasi barattimur dengan posisi kepala berada di sebelah timur sehingga ketika bangun menghadap ke barat. Arah Barat sebagai sebagai arah matahari terbenam merupakan simbol arah kematian. Pada masa kemudian, ada gelombang kedatangan orang Austronesia yang mengenal penguburan dengan wadah menyerupai bentuk perahu. Wadah penguburan tersebut masih berlangsung hingga kini, sekaligus sebagai simbol kendaraan arwah.

Dalam upacara adat Kaharingan, arwah leluhur hadir dengan menggunakan kendaraan berupa perahu arwah. Keberadan perahu ini juga berkaitan dengan perjalanan leluhur. Konsep religi sebagai salah satu unsur budaya mampu bertahan lebih lama daripada unsur budaya yang lain karena religi sebagai warisan leluhur telah menyatu sebagai motivasi yang kuat dan mendalam. Namun demikian, kepercayaan terhadap roh leluhur perlahan mulai ditinggalkan. Namun, ada yang masih bertahan, seperti upacara kelahiran, perkawinan, pengobatan, dan panen, dengan menghadirkan simbol-simbol leluhur. Meskipun telah banyak perubahan, Kaharingan sebagai kepercayaan leluhur telah melekat erat sebagai identitas orang Dayak hingga kini.

\section{DAFTAR PUSTAKA}

Alam, Bachtiar. 2014. "Globalisasi Dan Perubahan Budaya: Perspektif Teori Kebudayaan." Antropologi Indonesia 0(54):1-11.

Aubert, M., P. Setiawan, A. A. Oktaviana, A. Brumm, P. H. Sulistyarto, E. W. Saptomo, B. Istiawan, T. A. Ma'rifat, V. N. Wahyuono, F. T. Atmoko, J. X. 
Zhao, J. Huntley, P. S. C. Taçon, D. L. Howard, and H. E. A. Brand. 2018. "Palaeolithic Cave Art in Borneo." Nature 564(7735):254-57.

Baier, Martin. 2007. "The Development of the Hindu Kaharingan Religion: A New Dayak Religion in Central Kalimantan." Anthropos 102(2):56670.

Bellwood, Peter. 2000. Prasejarah Kepulauan Indo-Malaysia. Jakarta: Gramedia Pustaka Utama.

Bellwood, Peter. 2016. "Austronesian Studies in 2016: Where We Are Now?" Pp. 7-24 in Austronesian Diaspora a New Perspective, edited by T. S. Bagyo Prasetyo, Titi Surti Nastiti. Yogyakarta: Gadjah Mada University Press.

Bondan, Amir Hasan Kiai. 1953. Suluh Sejarah Kalimantan. Banjarmasin: MAT Percetaka Fadjar.

Fajari, Nia Marniati Etie, Gregorius Dwi Kuswanta, . Eko Haryono, M.Si. Muhammad Wishnu Wibisono, Delta Bayu Murti, Ulce Oktrivia, Eko Herwanto. 2019. Penelitian Arkeologi Prasejarah Kotabaru: Sebaran Situs Dan Hubungan Antarsitus Gua Di Wilayah Pesisir Kalimantan Bagian Tenggara. Banjarbaru.

Geertz, Clifford. 2012. "Agama Sebagai Sistem Kebudayaan.” Pp. 327-72 in Seven Theories of Religion, edited by Daniel L. Pals. Jogyakarta: IRCiSoD.

Geertz, Clifford. 1973. The Interpretation of Culture. New York: Basic Book.

Gerritsen, Fokke. 2008. "Archaeological Perspektif on Local Communities." Pp. 141-51 in A Companion to Archaeology, edited by J. Bintliff. Blackwell Publishing.

Hartatik. 2002a. "Keseimbangan Kosmos Dalam Kehidupan Masyarakat Dayak
Ngaju Di Kalimantan Tengah.” Naditira Widya (8):65-72.

Hartatik. 2002b. Penelitian Etnoarkeologi Bangunan Kubur Dayak Ngaju Di Parenggean Dan Mentaya Hulu, Kab. Kotawaringin Timur, Kalimantan Tengah. Banjarbaru.

Hartatik. 2006. "Penelitian Etnoarkeologi Suku Dayak Di Kalimantan." Naditira Widya (Edisi Khusus) (15):71-87.

Hartatik. 2017. Jejak Budaya Dayak Meratus Dalam Perspektif Etnoreligi. edited by B. Sulistyanto. Yogyakarta: Penerbit Ombak.

Keesing, Roger M. 1990. "Theories Of Culture Revisited." Canberra Anthropology 13(2):46-60.

Koentjaraningrat. 2000. Pengantar Ilmu Antropologi. Jakarta: PT Rineka Cipta.

Kusmartono, Vida Pervaya Rusianti. 2005. "The Sandong of the Ngaju Mortuary Variability in Southern Kalimantan. Thesis." The Australian National University, Canberra.

Rampai, Kiwok D. 1983. "Bangunan Makam Orang Ngaju Di Kalimantan Tengah, Suatu Studi Ethnoarkeologi. Skripsi." Universitas Gadjah Mada, Yogyakarta.

Schärer, Hans. 1963. Ngaju Religion The Conception of God among a South Borneo People. The Hague: Martinus

Simanjuntak, Truman. 2011. "Austronesia Prasejarah Di Indonesia.” Pp. 1-22 in Austronesia dan Melanesia di Nusantara, edited by Irfan Mahmud \& Erlin Novita. Yogyakarta: Ombak $\&$ Balai Arkeologi Jayapura.

Tanudirjo, DA. 2005. "Budaya Bahari Austronesia." Workshop Prasimposium Internasional Tentang Austronesia. LIPI. 
Tanudirjo, Daud Aris. 2016. "Mempertanyakan Austronesia Meneguhkan Identitas Indonesia." Pp. 11-29 in Jejak Austronesia di Indonesia, edited by Haryy Widianto. Yogyakarta: Gadjah Mada University Press.

Widianto, Harry dan Retno Handini. 2003.

"Karakter Budaya Prasejarah Di Kawasan Gunung Batubuli, Kalimantan Selatan: Mekanisme Hunian Gua Pasca Pleistosen.” Berita Penelitian Arkeologi Balai Arkeologi Banjarmasin 12:52-69.
Yondri, Lutfi. 2003. Laporan Penelitian Studi Etnoarkeologi Pada Masyarakat Dayak Selako, Desa Pajintan Dan Sekitarnya, Kec. Singkawang Timur Kabupaten Singkawang, Kalimantan Barat. Bandung.

\section{HASIL DISKUSI}

$>$ Tidak ada pertanyaan 